\title{
Studies on Genetic Divergence and Canonical Analysis in Slender Grain Rice (Oryza sativa L.)
}

\author{
Kalpataru Nanda ${ }^{1 *}$, D. N. Bastia ${ }^{1}$ and Ashutosh Nanda $^{2}$ \\ ${ }^{1}$ Department of Plant Breeding \& Genetics, O.U.A.T, Bhubaneswar, India \\ ${ }^{2}$ Department of Bioinformatics, O.U.A.T, Bhubaneswar, India \\ *Corresponding author
}

\begin{tabular}{l} 
K e y w o r d s \\
$\begin{array}{l}\text { Slender grain, genetic } \\
\text { divergence, }{ }^{2} \text { Statistic, } \\
\text { Tocher's method, } \\
\text { Canonical analysis, } \\
\text { transgressive segregants }\end{array}$ \\
Article Info \\
$\begin{array}{l}\text { Accepted: } \\
\text { 22 July } 2019 \\
\text { Available Online: } \\
\text { 10 August } 2019\end{array}$ \\
\hline
\end{tabular}

\section{Introduction}

Rice, the most widely grown and consumed cereal crop, is the lifeline for more than half of the world's population. It is the staple food for more than $65 \%$ of Indian population contributing approximately $40 \%$ to the total food grain production, occupying a pivotal role in the food, nutrition and livelihood security of the people. The country has the world's largest area under rice i.e., about 44 Mha and the second highest production i.e., about $165 \mathrm{Mt}$ at productivity of $3.65 \mathrm{t} / \mathrm{ha}$.
The present experiment was carried out using twenty-nine elite breeding lines from Station Yield Trial - Slender Grain materials along with three check varieties at the Rice Research Station, O.U.A.T., Bhubaneswar in kharif- 2016. A part of the research was to study the genetic divergence among the breeding lines used in the experiment. The $\mathrm{D}^{2}$ values obtained from the divergence study ranged from 3.36 between OR2675-6-4 and OR2676-2-5 to 2518 between OR2675-2-1 and Samba mahsuri. Following Tocher's method, all the thirty-two genotypes were classified into five different non-overlapping clusters. Cluster I contained twenty genotypes, Cluster II \& III contained five genotypes each while cluster IV \& V contained check varieties Ranidhan and Samba mahsuri respectively. The graph constructed by canonical analysis were broadly in agreement with the magnitude of divergence measured by $\mathrm{D}^{2}$ statistic, thus very well corroborating the grouping by Tocher' s method. Selection of parents should be done from the more divergent clusters for future hybridization program for getting better segregants. 
importance of genetic diversity in selecting parents to recover transgressive segregants has been repeatedly emphasized by many workers (Archana Devi et al., 2017). The present study was undertaken with the objective to access the genetic diversity of rice germplasm and identification of better genotypes for yield and yield attributing traits in slender grain rice.

\section{Materials and Methods}

Twenty-nine fixed breeding lines from the experimental materials of Station Yield Trial (Slender Grain) along with three check varieties viz., Ranidhan, Samba mahsuri and Jajati were planted at E-Block-1, Rice Research Station, O.U.A.T., Bhubaneswar during 2016 Kharif season. The experimental materials were put in a Randomized Block Design with two replications and raised in plots each measuring $1.53 \mathrm{~m}^{2}$ in area. Each plot was made up of three rows with each row consisting of seventeen plants. The row-torow and plant-to-plant spacing was maintained at $20 \mathrm{~cm} \times 15 \mathrm{~cm}$ and recommended crop management practices were followed. Observations were recorded for nine metric traits taking five competitive plants selected randomly from middle rows of each plot; whereas, characters like plot yield and days to $50 \%$ flowering were recorded on plot basis. The characters studied were plant height, days to $50 \%$ flowering, number of effective tillers/plant, flag leaf area, panicle length, number of fertile grains/panicle, fertility percentage, 100 grain weight and plot yield. The whole details of genotypes and their parentage are given in table 1.

The replicated data were subjected to statistical analysis, and then genetic divergence was computed by using Mahalanobi's generalized distance, $\mathrm{D}^{2}$ statistic as described by Rao (1952). The divergence between any two variables was obtained as the sum of the squares of differences in the values of corresponding transformed values. The possible pairs of $\mathrm{D}^{2}$ values are calculated from the thirty-two genotypes. Following Tocher's method as described by Rao (1952), the genotypes were grouped into clusters.

Canonical analysis was done according to Anderson (1958). The divergences of thirtytwo rice genotypes were represented in twodimensional graph using first two canonical vectors $\left(Z_{1}\right.$ and $\left.Z_{2}\right)$ as coordinates.

\section{Results and Discussion}

From the analysis of variance, it was observed that there exist high significant differences among the test genotypes for all the morphological characters under study. For assessing the genetic divergence among all the thirty-two genotypes by $\mathrm{D}^{2}$ analysis, variations in all the nine characters were used. The observed variability of $\mathrm{D}^{2}$ values ranged from 3.36 between OR2675-6-4 and OR2676-2-5 to 2518 between OR2675-2-1 and Samba mahsuri. Analysis of the $\mathrm{D}^{2}$-data showed that some genotypes were genetically close to each other while the rest are distinctly dissimilar or diverse. The highest distance observed between OR2675-2-1 and Samba mahsuri may be due to the wide difference in all the characters except for number of effective tillers/plant.

\section{Clustering pattern}

By Tocher's method, all the thirty-two rice genotypes were classified into five different non-overlapping clusters (Table-2). Cluster I contained twenty genotypes, Cluster II \& III contained five genotypes each while cluster IV \& V contained check varieties Ranidhan and Samba mahsuri respectively. Studying the average inter-cluster distances indicated that cluster II and V are more divergent from each other with an inter cluster distance 2270.42 while Cluster I and IV were less divergent 
from each other with inter-cluster distance 289.65. Closely observing the clustering pattern and the parentage of the thirty-two genotypes used, interesting results were found. Even though certain genotypes had the same parental combination they were grouped in different clusters for example both OR2659-5 \& OR2659-7 had same parentage (IR72 / Martha fine) but were grouped in cluster III \& I respectively. Similarly OR2674-13 \& OR2674-14-1 had same parentage (CRMS 32A / OR1889-5) but were grouped in III \& II respectively. At the same time a single cluster also housed genotypes of different parental combination for example cluster I had twenty different genotypes with four different parental combinations viz. IR72 / Martha fine, CRMS 32A / OR1889-5, CRMS 32A / OR2324-18, CRMS 32A / OR234519. All the ten genotypes originated from the cross CRMS 32A / OR234519 were grouped in cluster I while fifteen genotypes originating from cross CRMS 32A / OR2324-18 were grouped in 3 different clusters (Cluster- I, II \& III). Similar findings were also reported by Nisar et al., (2017) and Krishnamurthy et al., (2017).

A study of the cluster means of all the characters represented in (Table-4) indicated, genotypes in cluster I were characterized by medium duration with tallest plant height, longest panicle length, largest flag leaf area, moderate number of effective tillers/plant and moderate grain weight. Genotypes in Cluster II were characterized by short duration, tall plant height, low filled grains per panicle, larger flag leaf area, better fertility percentage and having highest grain weight.

Cluster III is characterized by short duration, tall plants, moderate flag leaf area and number of effective tillers/plant, highest number of filled grains per panicle with higher fertility percentage but with lower grain weight. Cluster IV is characterized by short height plants, short panicle but with moderate number of filled grains per panicle, highest fertility \%, number of effective tillers/plant and grain weight than others thus giving the highest yield. Cluster V is characterized by tall height plants with lowest values for number of effective tillers, number of filled grains per panicle, fertility $\%$, and grain weight thus giving the lowest yield.

\section{Canonical analysis}

The two canonical roots accounted for $81.6 \%$ of the total variability, thus qualifying for graphical presentation (Table-5). The mean values of the first two canonical vectors $Z_{1}$ and $\mathrm{Z}_{2}$ (Table-6) were used as coordinates in plotting a two-dimensional dispersion complex (Fig.1).

The grouping obtained through $\mathrm{D}^{2}$ analysis are super imposed on the two dimensional representation of the genotypes by canonical analysis. The scattered points on the $\mathrm{Z}_{1}-\mathrm{Z}_{2}$ graph were broadly in agreement with the magnitude of divergence measured by $\mathrm{D}^{2}$ statistic, thus very well corroborating the grouping by Tocher's method.

\section{Contribution of characters to genetic divergence}

The coefficients of the first two canonical vectors $\left(Z_{1}\right.$ and $\left.Z_{2}\right)$ presented in (Table-5) reflects relative importance of the characters contributing towards divergence. It was observed that the important characters responsible for genetic divergence were 100grain weight $\&$ fertility percentage in the first axis and days to $50 \%$ flowering, panicle length and grain yield in the second axis in that order, thus suggesting much difference among the test entries with respect to these traits.

Generally, geographical diversity has been considered as an index of genetic diversity. 
Table.1 Details of the 32 rice genotypes used in the study

\begin{tabular}{|l|l|l|}
\hline SI. No. & Genotype Designation & \multicolumn{1}{|c|}{ Cross Combination } \\
\hline $\mathbf{1}$ & OR2659-5 & IR 72 / Martha fine \\
\hline $\mathbf{2}$ & OR2659-7 & IR 72 / Martha fine \\
\hline $\mathbf{3}$ & OR2674-13 & CRMS 32A / OR 1889-5 \\
\hline $\mathbf{4}$ & OR2674-14-1 & CRMS 32A / OR 1889-5 \\
\hline $\mathbf{5}$ & OR2675-1-1 & CRMS 32A / OR2324-18 \\
\hline $\mathbf{6}$ & OR2675-1-2 & CRMS 32A / OR2324-18 \\
\hline $\mathbf{7}$ & OR2675-2-1 & CRMS 32A / OR2324-18 \\
\hline $\mathbf{8}$ & OR2675-2-2 & CRMS 32A / OR2324-18 \\
\hline $\mathbf{9}$ & OR2675-2-3 & CRMS 32A / OR2324-18 \\
\hline $\mathbf{1 0}$ & OR2675-2-4 & CRMS 32A / OR2324-18 \\
\hline $\mathbf{1 1}$ & OR2675-2-5 & CRMS 32A / OR2324-18 \\
\hline $\mathbf{1 2}$ & OR2675-2-6 & CRMS 32A / OR2324-18 \\
\hline $\mathbf{1 3}$ & OR2675-3-1 & CRMS 32A / OR2324-18 \\
\hline $\mathbf{1 4}$ & OR2675-3-2 & CRMS 32A / OR2324-18 \\
\hline $\mathbf{1 5}$ & OR2675-4-1 & CRMS 32A / OR2324-18 \\
\hline $\mathbf{1 6}$ & OR2675-5-1 & CRMS 32A / OR2324-18 \\
\hline $\mathbf{1 7}$ & OR2675-5-2 & CRMS 32A / OR2324-18 \\
\hline $\mathbf{1 8}$ & OR2675-6-4 & CRMS 32A / OR2324-18 \\
\hline $\mathbf{1 9}$ & OR2675-6-7 & CRMS 32A / OR2324-18 \\
\hline $\mathbf{2 0}$ & OR2676-1-1 & CRMS 32A / OR 234519 \\
\hline $\mathbf{2 1}$ & OR2676-1-2 & CRMS 32A / OR 2345-19 \\
\hline $\mathbf{2 2}$ & OR2676-1-4 & CRMS 32A / OR 2345-19 \\
\hline $\mathbf{2 3}$ & OR2676-2-3 & CRMS 32A / OR 2345-19 \\
\hline $\mathbf{2 4}$ & OR2676-2-4 & CRMS 32A / OR 2345-19 \\
\hline $\mathbf{2 5}$ & OR2676-2-5 & CRMS 32A / OR 2345-19 \\
\hline $\mathbf{2 6}$ & OR2676-2-6 & CRMS 32A / OR 2345-19 \\
\hline $\mathbf{2 7}$ & OR2676-3-1 & CRMS 32A / OR 2345-19 \\
\hline $\mathbf{2 8}$ & OR2676-3-2 & CRMS 32A / OR 2345-19 \\
\hline $\mathbf{2 9}$ & OR2676-4-2 & CRMS 32A / OR 2345-19 \\
\hline $\mathbf{3 0}$ & Ranidhan & Swarna / ORR 48-1 \\
\hline $\mathbf{3 1}$ & Samba mahsuri & GEB 24 / T(N) 1 \\
\hline $\mathbf{3 2}$ & Jajati & Rajeswari / T 141 \\
\hline & & \\
\hline
\end{tabular}


Table.2 Distribution of the 32 rice genotypes into different Clusters

\begin{tabular}{|l|l|l|}
\hline Cluster & $\begin{array}{c}\text { Number } \\
\text { of } \\
\text { genotypes }\end{array}$ & \multicolumn{1}{|c|}{ Name of genotypes } \\
\hline I & $\mathbf{2 0}$ & $\begin{array}{l}\text { OR2675-6-4, OR2676-2-5, OR2676-1-4, OR2676-2-6, } \\
\text { OR2676-1-2, OR2676-4-2, OR2676-1-1, OR2676-2-3, } \\
\text { OR2676-3-1, OR2675-2-4, OR2675-2-5, OR2675-3-1, } \\
\text { OR2676-3-2, OR2675-1-1, OR2675-3-2, OR2675-4-1, } \\
\text { OR2675-5-2, OR2675-2-2, OR2659-7, OR2676-2-4, }\end{array}$ \\
\hline II & $\mathbf{5}$ & $\begin{array}{l}\text { OR2675-2-1, OR2675-2-3, OR2675-2-6, OR2675-6-7, } \\
\text { OR2674-14-1 }\end{array}$ \\
\hline III & $\mathbf{5}$ & OR2675-1-2, OR2675-5-1, Jajati, OR2659-5, OR2674-13 \\
\hline IV & $\mathbf{1}$ & Ranidhan \\
\hline $\mathbf{V}$ & $\mathbf{1}$ & Samba mahsuri \\
\hline
\end{tabular}

Table.3 Estimates of intra-cluster distances $\left(\mathrm{D}^{2}\right)$ (bold) \& inter-cluster distances $\left(\mathrm{D}^{2}\right)$ (unbold) for the 32 rice genotypes

\begin{tabular}{|c|c|c|c|c|c|}
\hline Cluster & I & II & III & IV & V \\
\hline I & $\mathbf{1 5 9 . 1 5}$ & 471.82 & 313.34 & 289.65 & 1032.19 \\
\hline II & & $\mathbf{1 2 9 . 8 6}$ & 926.33 & 381.22 & 2270.42 \\
\hline III & & & $\mathbf{1 2 4 . 7 9}$ & 593.17 & 598.55 \\
\hline IV & & & & $\mathbf{0 . 0 0}$ & 1213.69 \\
\hline $\mathbf{V}$ & & & & & $\mathbf{0 . 0 0}$ \\
\hline
\end{tabular}

Table.4 Cluster means of 32 rice genotypes for all the 9 characters studied

\begin{tabular}{|l|l|c|c|c|c|c|}
\hline $\begin{array}{l}\text { Sl. } \\
\text { number }\end{array}$ & Clusters/Characters & I & II & III & IV & V \\
\hline $\mathbf{1 .}$ & Days to 50\% flowering & 91.47 & 84.00 & 86.20 & 97.00 & 101.00 \\
\hline $\mathbf{2 .}$ & Plant height $(\mathrm{cm})$ & 119.70 & 111.80 & 119.30 & 76.00 & 76.00 \\
\hline $\mathbf{3 .}$ & Flag leaf area $\left(\mathrm{cm}^{2}\right)$ & 50.47 & 47.24 & 39.98 & 25.40 & 30.80 \\
\hline $\mathbf{4 .}$ & Number of tiller/plant & 9.93 & 9.20 & 9.00 & 12.00 & 8.50 \\
\hline $\mathbf{5 .}$ & Panicle length $(\mathrm{cm})$ & 26.77 & 25.76 & 25.63 & 22.50 & 18.10 \\
\hline $\mathbf{6 .}$ & Number of filled grains/panicle & 189.91 & 155.31 & 221.95 & 199.30 & 127.45 \\
\hline $\mathbf{7 .}$ & Fertility \% & 77.07 & 78.21 & 77.05 & 81.10 & 72.80 \\
\hline $\mathbf{8 .}$ & 100 grain weight $(\mathrm{g})$ & 1.99 & 2.39 & 1.66 & 2.24 & 1.39 \\
\hline $\mathbf{9 .}$ & Grain yield (q/ha) & 38.78 & 32.68 & 37.34 & 45.75 & 24.51 \\
\hline
\end{tabular}


Table.5 Coefficient of the first two canonical vectors (Z1 and Z2) for all the 9 characters studied

\begin{tabular}{|l|l|c|c|}
\hline SI. Number & Characters & $\mathbf{Z}_{\mathbf{1}}$ & $\mathbf{Z}_{\mathbf{2}}$ \\
\hline $\mathbf{1}$ & Days to 50\% flowering & -.199 & $\mathbf{. 7 2 2}$ \\
\hline $\mathbf{2}$ & Plant height $(\mathrm{cm})$ & .028 & $\mathbf{. 1 3 9}$ \\
\hline $\mathbf{3}$ & Number of effective tillers/plant & .030 & $\mathbf{. 2 9 4}$ \\
\hline $\mathbf{4}$ & Flag leaf area $\left(\mathrm{cm}^{2}\right)$ & .038 & $\mathbf{. 0 5 6}$ \\
\hline $\mathbf{5}$ & Panicle length $(\mathrm{cm})$ & .013 & $\mathbf{. 3 9 1}$ \\
\hline $\mathbf{6}$ & Number of filled grains/panicle & -.115 & $\mathbf{. 1 9 2}$ \\
\hline $\mathbf{7}$ & Fertility \% & .084 & $\mathbf{. 0 4 6}$ \\
\hline $\mathbf{8}$ & 100 grains weight $(\mathrm{g})$ & .953 & $\mathbf{. 1 9 1}$ \\
\hline $\mathbf{9}$ & Grain yield $(\mathbf{q} / \mathbf{h a})$ & $\mathbf{. 1 7 0}$ & $\mathbf{. 3 7 6}$ \\
\hline
\end{tabular}

Table.6 Mean canonical values of the vectors $\left(Z_{1} \& Z_{2}\right)$ of the 32 rice genotypes under study

\begin{tabular}{|c|c|c|}
\hline Variety & $\mathbf{Z}(\mathbf{1})$ & $\mathbf{Z}(\mathbf{2})$ \\
\hline $\mathbf{1}$ & 36.55 & 87.39 \\
\hline $\mathbf{2}$ & 47.23 & 89.58 \\
\hline $\mathbf{3}$ & 42.04 & 89.07 \\
\hline $\mathbf{4}$ & 63.75 & 84.35 \\
\hline $\mathbf{5}$ & 53.67 & 90.07 \\
\hline $\mathbf{6}$ & 44.44 & 85.79 \\
\hline $\mathbf{7}$ & 72.27 & 93.67 \\
\hline $\mathbf{8}$ & 59.52 & 91.30 \\
\hline $\mathbf{9}$ & 73.39 & 92.67 \\
\hline $\mathbf{1 0}$ & 54.37 & 91.53 \\
\hline $\mathbf{1 1}$ & 57.92 & 93.07 \\
\hline $\mathbf{1 2}$ & 70.89 & 92.74 \\
\hline $\mathbf{1 3}$ & 48.58 & 90.48 \\
\hline $\mathbf{1 4}$ & 49.75 & 90.03 \\
\hline $\mathbf{1 5}$ & 48.47 & 89.56 \\
\hline $\mathbf{1 6}$ & 41.88 & 86.41 \\
\hline $\mathbf{1 7}$ & 56.05 & 89.34 \\
\hline $\mathbf{1 8}$ & 50.12 & 101.03 \\
\hline $\mathbf{1 9}$ & 64.71 & 92.43 \\
\hline $\mathbf{2 0}$ & 45.06 & 96.92 \\
\hline $\mathbf{2 1}$ & 44.55 & 99.28 \\
\hline $\mathbf{2 2}$ & 48.58 & 100.02 \\
\hline $\mathbf{2 3}$ & 51.13 & 99.96 \\
\hline $\mathbf{2 4}$ & 56.66 & 97.73 \\
\hline $\mathbf{2 5}$ & 50.05 & 102.44 \\
\hline $\mathbf{2 6}$ & 55.06 & 102.43 \\
\hline $\mathbf{2 7}$ & 44.54 & 102.90 \\
\hline $\mathbf{2 8}$ & 50.21 & 95.3 \\
\hline $\mathbf{2 9}$ & 56.83 & 100.43 \\
\hline $\mathbf{3 0}$ & 63.43 & 95.75 \\
\hline $\mathbf{3 1}$ & 23.30 & 94.64 \\
\hline $\mathbf{3 2}$ & 38.71 & 87.47 \\
\hline & & \\
\hline
\end{tabular}


Fig.1 Mean value of $1^{\text {st }}$ two canonical vectors for 32 rice genotypes

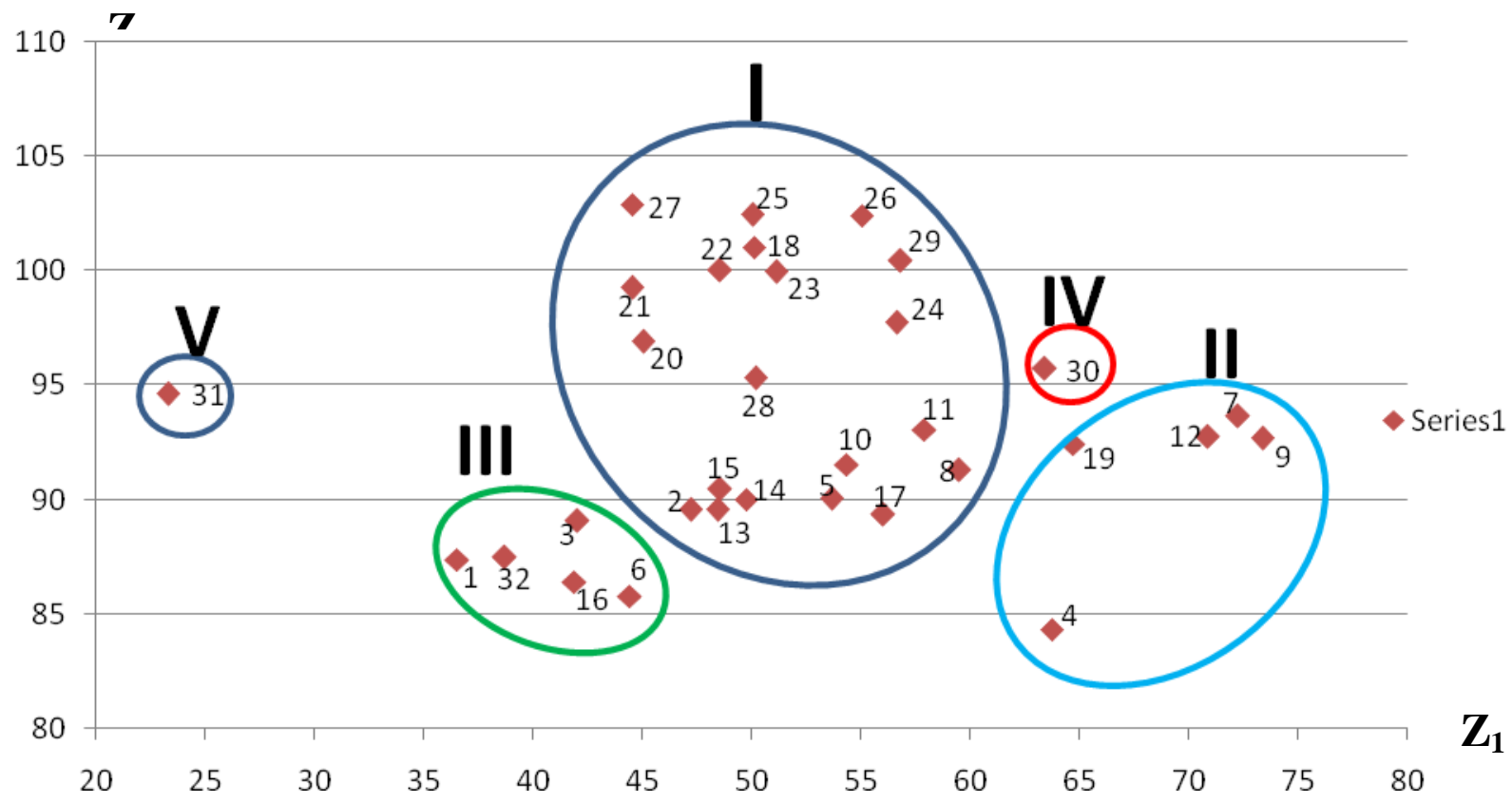

Two-dimensional representation of 32 rice genotypes, using the $1^{\text {st }}$ two canonical vectors $Z_{1} \& Z_{2}$ as coordinates

Published reports are highly conflicting with regard to the relation between geographical origin and genetic diversity. A number of workers in rice found no parallelism between genetic diversity and eco-geographic distribution Behera et al., (2017), Maurya et al., (2017), Sowmiya et al., (2017), Vijay Kumar et al., (2015). The results obtained in the present study did not show the relationship between the two.

Thus it indicated that geographical distance per se is not that important in varietal diversity. It may be visualized that the genotypes developed at one location are showing similarity with those developed elsewhere. When divergence in the present study was analysed on the basis of yield and traits influencing the yield, it is apparently clear that the characters favoured by selection, whether artificial or natural, would greatly determine the genetic similarity or differences among the genotypes. It is further, evident that even selections made at a single location could lead to the development of diverse types depending upon the type of genes incorporated/assembled into the genotypes as well as the direction of selection.

In the present study, 100-grain weight, Days to $50 \%$ flowering, number of filled gains /panicle, panicle length and grain yield were found to be major characters contributing to varietal diversity. Similar results were reported by Sowmiya et al., (2017).

Divergence study indicated high genetic diversity among the genotypes under study. More divergent clusters are Cluster II and V followed by Cluster IV and V (Table 12). Hence selecting genotypes from these divergent clusters are important in hybridization programme to get better segregants

\section{References}

Ahmed H., Razvi S.M., Bhat M.A., Njeeb S., Wani N. and Habib M. 2010. Genetic variability and genetic divergence of 
important rice (Oryza sativa L.) varieties, International Journal of Current Research, 4: 33-37.

Behera M., Bastia D.N., Monalisha S.P. 2017. Genetic Divergence Analysis of some Genotypes of Aerobic Rice, Environment and Ecology, 35(4C): 3311-3314

Devi A., Kumari P., Dwivedi R., Dwivedi S., Verma O.P., Singh P.K. and Dwivedi D.K. 2017. Gene action and combining ability analysis for yield and yield contributing traits in rice (Oryza sativa L.) over environment. Journal of Pharmacognosy and Phytochemistry, 6(3): 662-671.

Iqbal T., Iqbal Hussain, Nauman M., Ali M., Saad Saeed, Ali F. 2018. Genetic variability, correlation and cluster analysis in elite lines of rice. Journal of Scientific Agriculture, 2: 85-91

Krishnamurthy et al., 2017. Identification of mega-environments and rice genotypes for general and specific adaptation to saline and alkaline stresses in India. Scientific Reports; 7(1): 7968

Mahalanobis, P.C., 1936. On the generalized distance in statistics. Poc. Nat. Inst. Sci. (India), 2: 49-55.

Maurya B.K., Singh P.K., Verma O.P. and Mandal D.K. 2017. Genetic Variability and Divergence Analysis in Rice (Oryza sativa L.) under Sodic Soil. International Journal of Current Microbiology and Applied Sciences, 6(10): 2865-2869

Nisar M., Kumar A., Pandey V.R., Singh P.K. and Verma O.P. 2017. Studies on genetic divergence analysis in rice (Oryza sativa L.) under sodic soil. International Journal of Current Microbiology and Applied Sciences, 6(12): 3351-3358

Pathak H., Samal P. and Shahid M. 2018. Revitalizing rice-systems for enhancing productivity, profitability and climate resilience. (Eds.) Rice research for enhancing productivity, profitability and climate resilience, ICAR-National Rice Research Institute, Cuttack, Odisha, p 117

Sowmiya C.A. and Venkatesan M. 2017. Studies on Genetic Diverity in Rice (Oryza sativa L.). International Journal of Current Microbiology and Applied Sciences, 6(9): 1749-1756

Vijay Kumar, 2015. Genetic diversity and character association studies for some economic traits in rice (Oryza sativa L.). An International Quarterly Journal of Life Sciences, 10(2): 899-904.

Zhou Y., Miao J., Gu M., Peng X., Leburu M. 2015. Natural Variations in SLG7 Regulate Grain shape. Genetics. 201(4)

\section{How to cite this article:}

Kalpataru Nanda, D. N. Bastia and Ashutosh Nanda. 2019. Studies on Genetic Divergence and Canonical Analysis in Slender Grain Rice (Oryza sativa L.). Int.J.Curr.Microbiol.App.Sci. 8(08): 2865-2872. doi: https://doi.org/10.20546/ijcmas.2019.808.330 